\title{
3-aminopropyl functionalized magnesium phyllosilicate as an organoclay based drug carrier for improving the bioavailability of flurbiprofen
}

This article was published in the following Dove Press journal:

International Journal of Nanomedicine

30 October 2013

Number of times this article has been viewed

\author{
Liang Yang' \\ Soo-Kyung Choi ${ }^{2}$ \\ Hyun-Jae Shin ${ }^{2}$ \\ Hyo-Kyung Han' \\ 'College of Pharmacy, Dongguk \\ University-Seoul, Siksa-dong, Ilsan- \\ Donggu, Goyang, Gyunggi-do, Korea; \\ ${ }^{2}$ Department of Chemical and \\ Biochemical Engineering, Chosun \\ University, Gwangju, Korea
}

\begin{abstract}
This study aimed to develop an oral delivery system using clay-based organicinorganic hybrid materials to improve the bioavailability of the drug, flurbiprofen, which is poorly soluble in water. 3-aminopropyl functionalized magnesium phyllosilicate (AMP clay) was synthesized by a one-pot direct sol-gel method, and then flurbiprofen (FB) was incorporated into AMP clay (FB-AMP) at different drug/clay ratios. The structural characteristics of AMP and FB-AMP formulation were confirmed by X-ray diffraction, Fourier transform infrared spectroscopy, and transmission electron microscopy. Among tested formulations, FB-AMP ${ }_{(3)}$, dramatically increased the dissolution of FB and achieved rapid and complete drug release within 2 hours. More than $60 \%$ of FB was released from FB-AMP ${ }_{(3)}$ after 30 minutes; the drug was completely dissolved in the water within 2 hours. Under the acidic condition $(\mathrm{pH}$ 1.2), FB-AMP ${ }_{(3)}$ also increased the dissolution of FB by up to $47.1 \%$ within 1 hour, which was three-fold higher than that of untreated FB. Furthermore, following an oral administration of $\mathrm{FB}_{-\mathrm{AMP}_{(3)}}$ to Sprague-Dawley rats, the peak plasma concentration and area under the plasma concentration-time curve of FB increased two-fold, and the time to reach the peak plasma concentration was shortened compared with that in the untreated FB. This result suggests that the oral drug delivery system using clay-based organic-inorganic hybrid material might be useful to improve the bioavailability of FB.
\end{abstract}

Keywords: poorly water-soluble drugs, aminopropyl functionalized magnesium phyllosilicate, organic clay, oral bioavailability

\section{Introduction}

Oral delivery is the most convenient and widely accepted route of drug administration, especially for chronic therapies in which repeated administrations are required. Oral formulations are used largely because of 1) patient compliance; 2) low invasive character; 3) easy administration; and 4) the low cost of the manufacturing processes. However, it has been estimated that anywhere from $40 \%$ to as much as $70 \%$ of all new chemical entities entering drug development programs possess insufficient aqueous solubility, leading to limited drug absorption. ${ }^{1}$ Therefore, there are continuous needs for efficient delivery systems that will improve the bioavailability of poorly soluble/ absorbable drugs.

Clay minerals of layered organic-inorganic hybrid materials resembling the talc parent structure $\mathrm{Si}_{8} \mathrm{Mg}_{6} \mathrm{O}_{20}(\mathrm{OH})_{4}$ have been synthesized by a sol-gel reaction in ambient conditions, with various combinations of metal ions such as magnesium, nickel, and zinc. ${ }^{2-5}$ Their organofunctionalities have also been extensively investigated to improve biocompatibility. For example, organoclay as 2:1 trioctahedral typed aminopropyl functionalized
Correspondence: Hyo-Kyung Han College of Pharmacy, Dongguk University-Seoul, Siksa-dong, IlsanDonggu, Goyang, Gyunggi-do, 4I0-820, Korea

$\mathrm{Tel}+823196 \mid 5217$

Fax +82319615206

Email hkhan@dongguk.edu 
magnesium phyllosilicate (AMP) has been synthesized by a one-pot sol-gel reaction under ambient conditions. ${ }^{6,7}$ This process results in organo-building blocks that are optically transparent due to the repulsion of protonated amine groups in aqueous media. The delaminated layers of AMP clay in aqueous solution are $30-150 \mathrm{~nm}$ in size and about 2-4 nm in thickness. The cationic and water-soluble properties of AMP clay have been used to construct hybrid materials with biomolecules and drug delivery systems. ${ }^{8-13}$ Considering AMP clay is a nontoxic host material, ${ }^{14}$ it should have high potential as a promising drug delivery carrier. There have been a few reports indicating the application of AMP clay as an efficient drug delivery system; ${ }^{9,11-13}$ however, most of the previous studies were limited to in vitro evaluation. Because there can be a significant gap between the in vitro and in vivo performance of drug delivery systems, the significance of in vitro observation should be clarified in appropriate in vivo systems. Therefore, in the present study, drug-loaded AMP clays have been synthesized and their in vitro, as well as in vivo, characteristics were evaluated. Because flurbiprofen (FB) is one of the widely used nonsteroidal anti-inflammatory drugs (NSAIDs) and is also poorly water-soluble, ${ }^{15}$ it was selected as a model drug. Subsequently, drug-loaded organoclays were synthesized at various drug-clay ratios, and their effects on the dissolution and bioavailability of the drug were examined in comparison with the conventional powder formulation.

\section{Materials and methods}

\section{Materials}

Flurbiprofen was obtained as a gift from Kolon Life Science Inc., (Seoul, Korea) and 3-aminopropyltriethoxysilane (99\%) was supplied by Sigma-Aldrich (St Louis, MO, USA). Ethanol, acetonitrile and methanol were purchased from Merck KGaA (Darmstadt, Germany). Magnesium chloride hexahydrate $(98.0 \%)$ and other common inorganic salts were obtained from Junsei Chemical Co., Ltd., (Tokyo, Japan). All other chemicals were of analytical grade and all solvents were of high-performance liquid chromatography (HPLC) grade.

\section{Preparation of FB-AMP clays}

3-aminopropyl-functionalized magnesium phyllosilicate clay (AMP clay) was prepared by the methods described in previous reports. ${ }^{9,11}$ In brief, magnesium chloride $(1.68 \mathrm{~g}$, $7.24 \mathrm{mmol}$ ) was dissolved in ethanol (40 g), and then 3-aminopropyltriethoxysilane $(2.6 \mathrm{~mL}, 11.7 \mathrm{mmol})$ was added dropwise with rapid stirring. A white precipitate formed almost immediately and was stirred overnight. The resulting product was isolated by centrifugation and washed in ethanol $(3 \times 50 \mathrm{~mL})$, before drying in air at $40^{\circ} \mathrm{C}$. Exfoliation of the AMP clay was undertaken by dispersing the bulk powder in water, followed by ultrasonication for 5 minutes.

To load FB into the AMP clay, an aqueous solution of FB $(1 \mathrm{~mL}, 10 \mathrm{mg} / \mathrm{mL})$ was added slowly to the exfoliated AMP suspension at the different drug/clay ratios $(1: 1,1: 2$, and 1:3) in various formulations: FB-AMP ${ }_{(1)}, \mathrm{FB}^{-\mathrm{AMP}_{(2)}}$, and FB-AMP $_{(3)}$. The product, which precipitated immediately, was left to age overnight and then separated by centrifugation and air-dried at room temperature.

\section{Structural characterization}

The structures of AMP clay and FB-AMP clay were confirmed by X-ray diffraction (XRD), Fourier transform infrared spectroscopy (FT-IR), and transmission electron microscopy (TEM). XRD patterns were obtained on an X-ray diffractometer (X'Pert PRO MPD; PANalytical Co, Eindhoven, The Netherlands) with $\mathrm{CuK} \alpha$ radiation at $20 \mathrm{~mA}$ and $40 \mathrm{kV}$. Powder samples were pressed onto a glass X-ray sample holder. Scans were recorded between $3^{\circ}$ and $70^{\circ}(2 \theta)$ with a step size of $0.05^{\circ}$ and scanning speed of $2 \%$ minute. FT-IR spectra of each sample were obtained on an IR-grade potassium bromide $(\mathrm{KBr})$ pellet (Nicolet 6700; Thermo Fisher Scientific, Waltham, MA, USA). TEM imaging was obtained on a bright field emission microscope (Tecnai G2; FEI, Hillsboro, OR, USA) with a LaB6 electron gun and an accelerating voltage of $200 \mathrm{kV}$.

\section{Dissolution studies}

Dissolution tests were conducted using the USP paddle method with $50 \mathrm{rpm}$ at $37^{\circ} \mathrm{C} \pm 0.5^{\circ} \mathrm{C}$ in the dissolution tester DT 1420 (ERWEKA GmbH, Heusenstamm, Germany). The drug release profile from the FB-AMP formulations was evaluated in water and compared to that taken from pure FB. In addition, $\mathrm{pH}$-dependency in the dissolution of the FB-AMP formulations was examined at $\mathrm{pH} \mathrm{1.2,} \mathrm{4.0,} \mathrm{and} \mathrm{6.8.} \mathrm{Each}$ formulation was exposed to the dissolution medium $(\mathrm{pH} 1.2$, 4.0, 6.8 buffer and water) for 2 hours. At the predetermined time points $(5,10,15,30,45,60$, and 120 minutes $), 1 \mathrm{~mL}$ of each sample was collected and filtered through a $0.45 \mu \mathrm{m}$ pore-sized PTFE syringe filter. After each sample collection, an equivalent amount of fresh medium was added to maintain the constant volume of dissolution media. The released drug amount was determined by HPLC assay.

\section{Animal studies}

Male Sprague-Dawley rats (250 g-300 g) were purchased from Samtako Bio Korea Co., Ltd. (Osan, Korea) and given 
free access to a normal standard chow diet (Superfeed Co., Ltd, Wonju, Korea) and tap water. All animal studies were carried out in accordance with the Guiding Principles in the Use of Animals in Toxicology adopted by the Society of Toxicology (USA), and the study protocol was approved by the review committee of Dongguk University (IACUC-2013007). Rats were fasted for 18 hours prior to the experiments and were given free access to tap water. The rats were then divided into two groups ( $\mathrm{n}=6$ per group) and orally given either FB (10 mg/kg) or FB-AMP formulation (equivalent to $10 \mathrm{mg} / \mathrm{kg}$ of FB). The drug was given as an aqueous suspension via an oral gavage. Blood samples were collected at 0.25 , $0.5,0.75,1,2,4,6$, and 12 hours. Blood samples were centrifuged at 15,000 rpm for 5 minutes, and the obtained plasma samples were stored at $-80^{\circ} \mathrm{C}$ until analyzed by HPLC.

\section{HPLC analysis}

\section{In vitro samples}

Drug concentration was measured by the HPLC method reported in previous studies. ${ }^{16,17}$ The HPLC system (Flexar; PerkinElmer, Waltham, MA, USA) consisted of an ultraviolet (UV) detector, an automatic injector, and two solvent delivery pumps. An octadecylsilane column (Gemini C18, $4.6 \times 150 \mathrm{~mm}, 5 \mu \mathrm{m}$; Phenomenex, Torrance, CA, USA) was eluted with a mobile phase consisting of acetonitrile/ water/phosphoric acid $(600 / 400 / 5, \mathrm{v} / \mathrm{v} / \mathrm{v})$. The flow rate was $1.5 \mathrm{~mL} /$ minute with the UV detection wavelength set at $254 \mathrm{~nm}$.

\section{In vivo samples}

To $50 \mu \mathrm{L}$ of plasma sample, $600 \mu \mathrm{L}$ of acetonitrile and $50 \mu \mathrm{L}$ of internal standard (valsartan, $10 \mu \mathrm{g} / \mathrm{mL}$ ) were added and mixed vigorously for 5 minutes. After centrifuging at $15,000 \mathrm{rpm}$ for 2 minutes, the supernatant was transferred into a microtube and evaporated under vacuum. The residue was reconstituted with $150 \mu \mathrm{L}$ of the mobile phase and after vigorous mixing for 1 minute, $50 \mu \mathrm{L}$ of the supernatant was injected into the HPLC system. An octadecylsilane column (Gemini C18, $4.6 \times 150 \mathrm{~mm}, 5 \mu \mathrm{m}$; Phenomenex) was eluted with a mobile phase consisting of acetonitrile/water/ phosphoric acid $(600 / 400 / 5, \mathrm{v} / \mathrm{v} / \mathrm{v})$. The flow rate was $1.5 \mathrm{~mL} /$ minute with the UV detection wavelength set at $254 \mathrm{~nm}$.

\section{Pharmacokinetic analysis and statistical analysis}

The plasma concentration data were analyzed by noncompartmental analysis using Kinetica version 5.0
(Thermo Fisher Scientific). The area under the plasma concentration-time curve (AUC) was calculated using the linear trapezoidal rule. The peak plasma concentration $\left(\mathrm{C}_{\max }\right)$ and the time to reach the peak plasma concentration $\left(\mathrm{T}_{\max }\right)$ were observed values from the experimental data.

All means were presented with their standard deviation. The statistical analysis was conducted using the Student's $t$-test; $P<0.05$ was considered statistically significant.

\section{Results and discussion Structural characterization X-ray powder diffraction}

AMP clay was readily prepared by co-condensation in an ethanolic solution containing magnesium chloride and 3-aminopropyltriethoxy silane. It consisted of a disordered talc-like 2:1 trioctahedral smectite structure with a central brucite octahedral sheet overlaid on both sides with a tetrahedral silicate network comprising covalently linked uncharged aminopropyl functionalities. The AMP clay was subsequently delaminated in water by protonation of the amino side chains to produce clear suspensions of micrometer-sized exfoliated sheets that could be restacked spontaneously into a bulk phase by addition of the anionic drug FB. The XRD data of AMP clay and $\mathrm{FB}-\mathrm{AMP}_{(3)}$ are shown in Figure 1. Corresponding powder X-ray diffraction patterns show in each case a broad $\mathrm{d}_{001}$ interlamellar reflection, indicating that layered structures were spontaneously reassembled in the presence of the FB molecules. The broad higher angle in-plane peaks included the characteristic $d_{060}$ smectite reflection at $59^{\circ}$ in $2 \theta(1.56 \AA)$ with dramatically increased intensity and confirmed that the structural framework of AMP clay was retained during the delamination/intercalation processes. Using Bragg's law, the basal spacing of AMP clay was calculated to be $14.73 \AA$. As a result of intercalation, the reflections (001) shifted to lower angles with an increase in the basal spacing (16.38 $\AA$ ). We therefore speculated that the drugs were incorporated within the organoclay galleries as a monolayer, with the molecular long axis parallel to the layer direction of the AMP structure (diameter of benzene ring, $0.28 \mathrm{~nm}$; size of one atom, $\sim 0.1 \mathrm{~nm})$.

\section{FT-IR data}

The typical IR absorption bands of AMP and FB-AMP are depicted in Figure 2. The covalently linked aminopropyl functionality ( $\mathrm{Si}-\mathrm{C}, 1,130 \mathrm{~cm}^{-1} ; \mathrm{NH}_{3}^{+}, 2,029 \mathrm{~cm}^{-1} ; \mathrm{N}-\mathrm{H}$, $1635 \mathrm{~cm}^{-1}, 1,512 \mathrm{~cm}^{-1}$ ) and phyllosilicate framework (Si-O-Si, 1,020 cm c $^{-1}$ Mg-O, Mg-O-Si, $565 \mathrm{~cm}^{-1}-497 \mathrm{~cm}^{-1}$ ) were retained after loading FB into the AMP clay. Interactions 


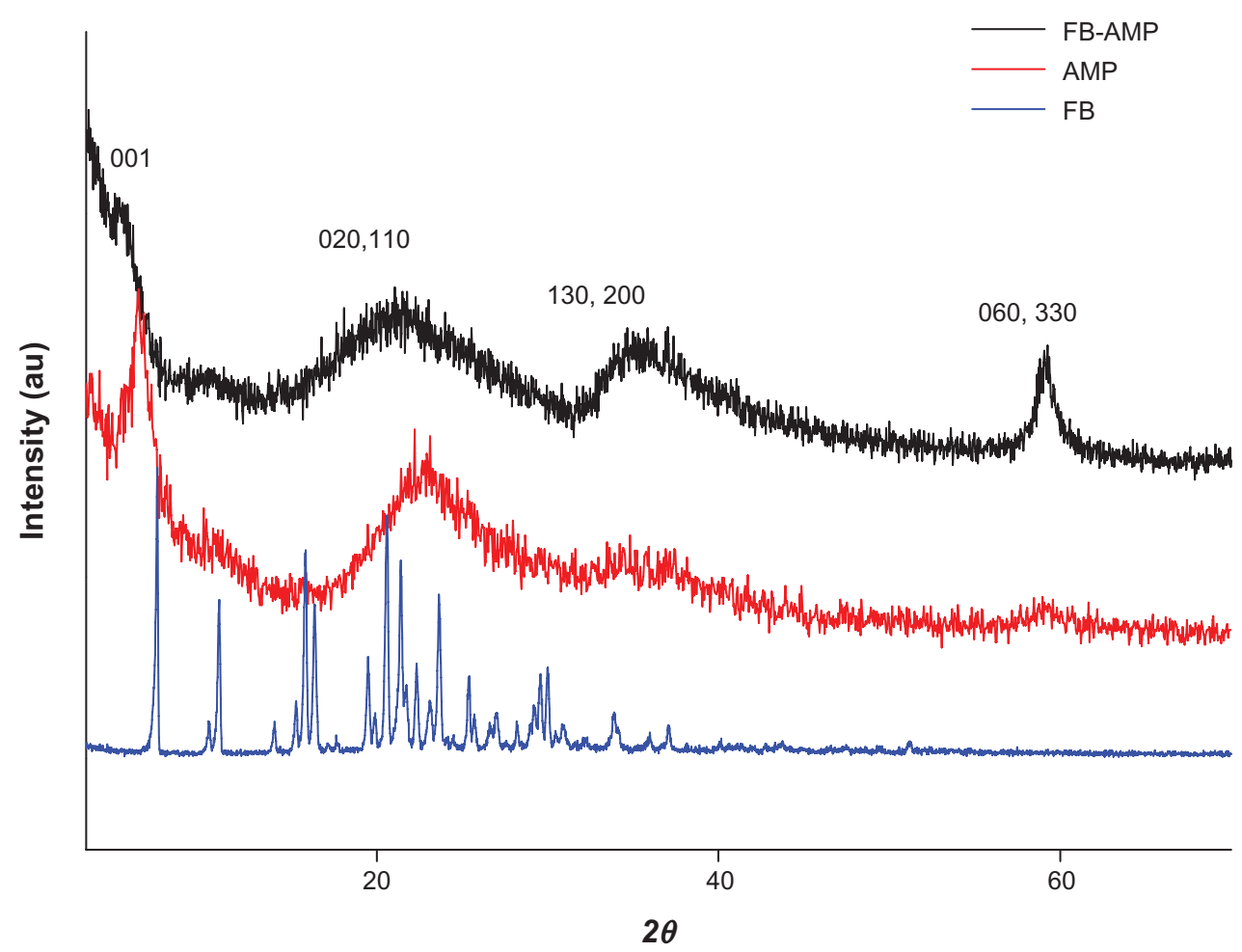

Figure I X-ray diffraction patterns of FB, AMP, and FB-AMP clay.

Abbreviations: FB, flurbiprofen; AMP, aminopropyl functionalized magnesium phyllosilicate; FB-AMP, flurbiprofen incorporated into 3-aminopropyl functionalized magnesium phyllosilicate clay.

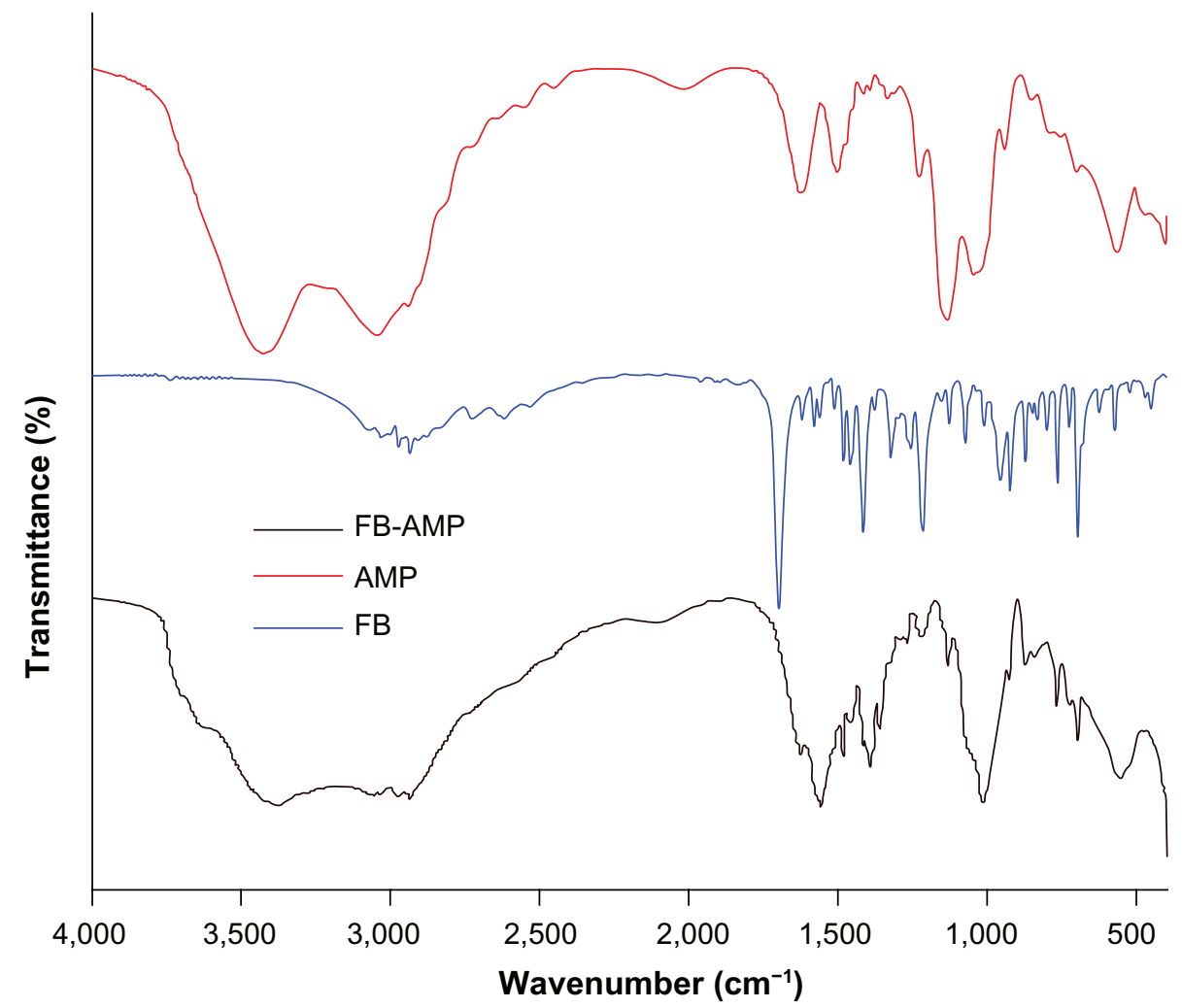

Figure 2 Fourier transform infrared spectroscopy (FT-IR) spectra of FB, AMP, and FB-AMP clay.

Abbreviations: FB, flurbiprofen; AMP, aminopropyl functionalized magnesium phyllosilicate; FB-AMP, flurbiprofen dissolved in AMP clay. 


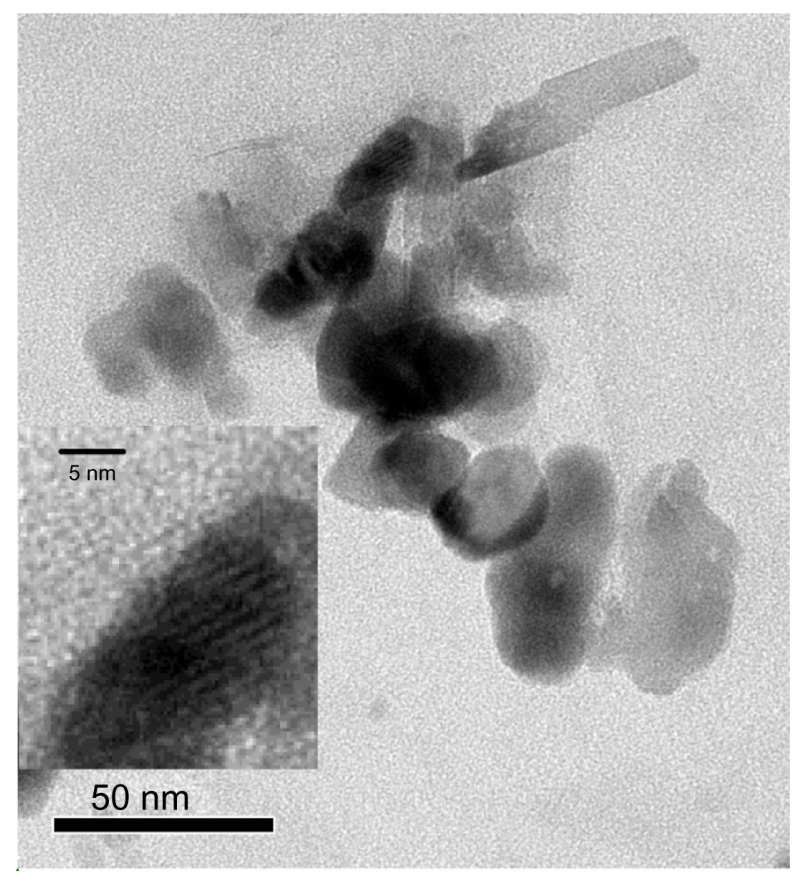

Figure 3 TEM image of $\mathrm{FB}-\mathrm{AMP}_{(3)}$. The inner, magnified figure shows the layered structure more clearly.

Abbreviations: TEM, transmission electron microscopy; FB-AMP, flurbiprofen incorporated into 3-aminopropyl functionalized magnesium phyllosilicate clay. between FB and aminopropyl groups of AMP clay were evidenced by shifts in the vibrational frequencies associated with particular absorption bands. For example, the bands of FB were at $1,701 \mathrm{~cm}^{-1}$ for the free carboxylic group, at $1,962 \mathrm{~cm}^{-1}$ for a substituted aromatic ring, and at $1,622 \mathrm{~cm}^{-1}$ for the $v(\mathrm{C}-\mathrm{C})$ stretching mode of the aromatic ring. As a result of intercalation of FB into AMP, new peaks were detected, such as symmetric and asymmetric modes of $\mathrm{COO}^{-}$at $1,419 \mathrm{~cm}^{-1}$ and $1,560 \mathrm{~cm}^{-1}$, respectively. Vibrations attributed to the aminopropyl side groups of the AMP were also shifted from $1,635 \mathrm{~cm}^{-1}$ (N-H deformation) and $2,029 \mathrm{~cm}^{-1}\left(\mathrm{NH}_{3}{ }^{+}\right.$stretch) to $1,625 \mathrm{~cm}^{-1}$ and $2,112 \mathrm{~cm}^{-1}$, respectively, indicating strong electrostatic interaction between FB and the surface of the AMP lamellae.

\section{TEM image}

The layered structure and terrace-like piled structure are shown in the TEM images (Figure 3), which confirms that the intercalated AMP clay with FB was synthesized. This means that the talc-like smectite structure of FB-AMP was retained during the modification.

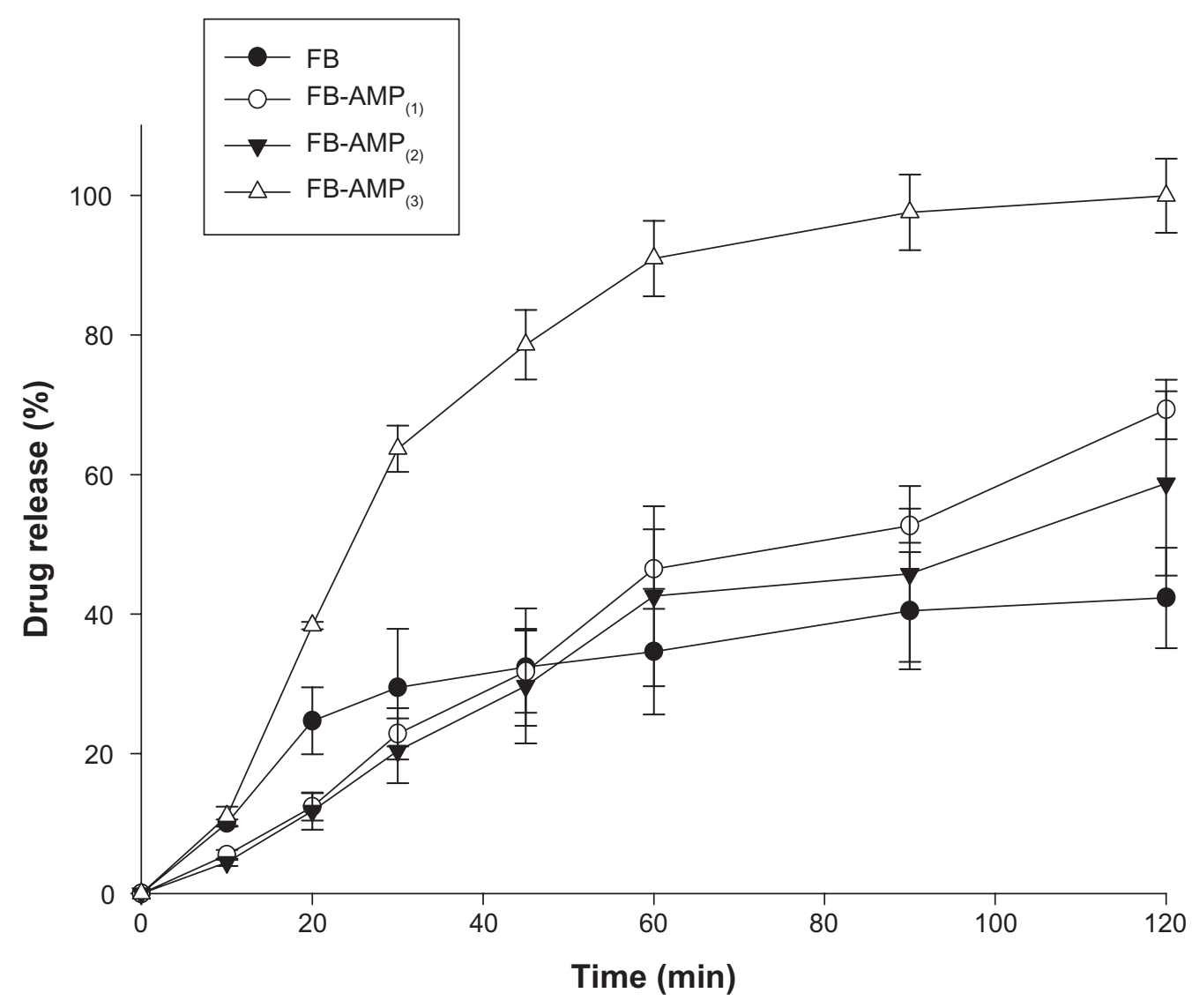

Figure 4 Drug release profiles of $F B$ and FB-AMP formulations in water (mean $\pm S D, n=3$ ).

Abbreviations: FB, flurbiprofen; FB-AMP, flurbiprofen incorporated into 3-aminopropyl functionalized magnesium phyllosilicate clay; SD, standard deviation; min, minutes. 


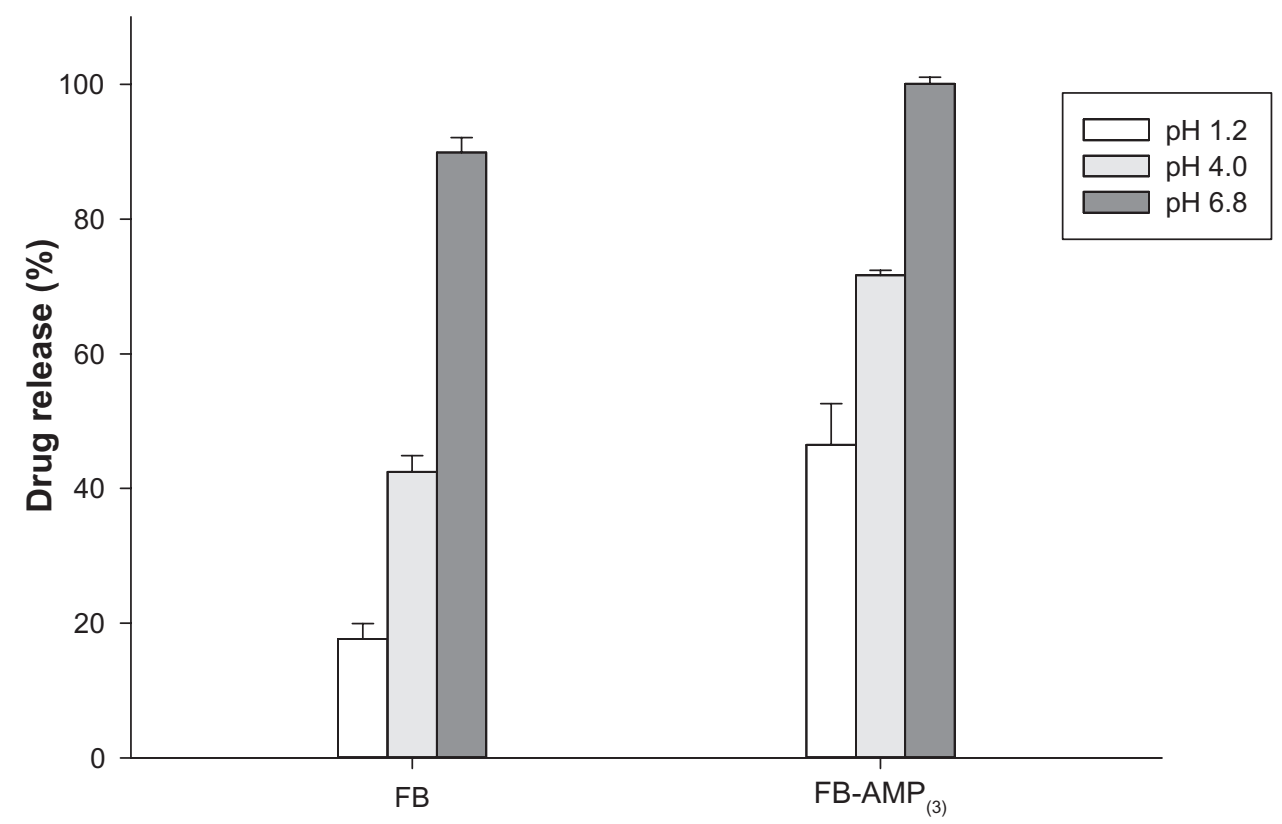

Figure $5 \mathrm{pH}$ dependency in the drug release from $\mathrm{FB}$ and $\mathrm{FB}-\mathrm{AMP}{ }_{(3)}$ (mean \pm standard deviation, $\mathrm{n}=3$ ).

Abbreviations: $\mathrm{FB}$, flurbiprofen; FB-AMP ${ }_{(3)}$, flurbiprofen incorporated into 3-aminopropyl functionalized magnesium phyllosilicate clay.

\section{In vitro characteristics of the}

\section{FB-AMP clay}

The dissolution profiles of FB-AMP clay were examined in water (Figure 4). Compared to other compositions, FB-AMP ${ }_{(3)}$ indicated rapid and complete drug release within 2 hours. More than $60 \%$ of FB was released from FB-AMP $(3)$ after 30 minutes, and all of the drug was completely dissolved within 2 hours, whereas the drug release from the untreated
FB was less than $40 \%$. This result suggests that $\mathrm{FB}-\mathrm{AMP}_{(3)}$ may be useful to improve the degree of drug release of FB.

The increased dissolution via FB-AMP ${ }_{(3)}$ may be explained, at least in part, as follows. FB-AMP ${ }_{(3)}$ should have a "salt sandwich" structure and the dissociation of positively charged AMP clay in aqueous solution drives the microenvironmental $\mathrm{pH}$ to be more basic ${ }^{18-20}$ and thus enhances the solubility of the acidic drug. On the other hand, FB-AMP ${ }_{(1)}$ and FB-AMP ${ }_{(2)}$

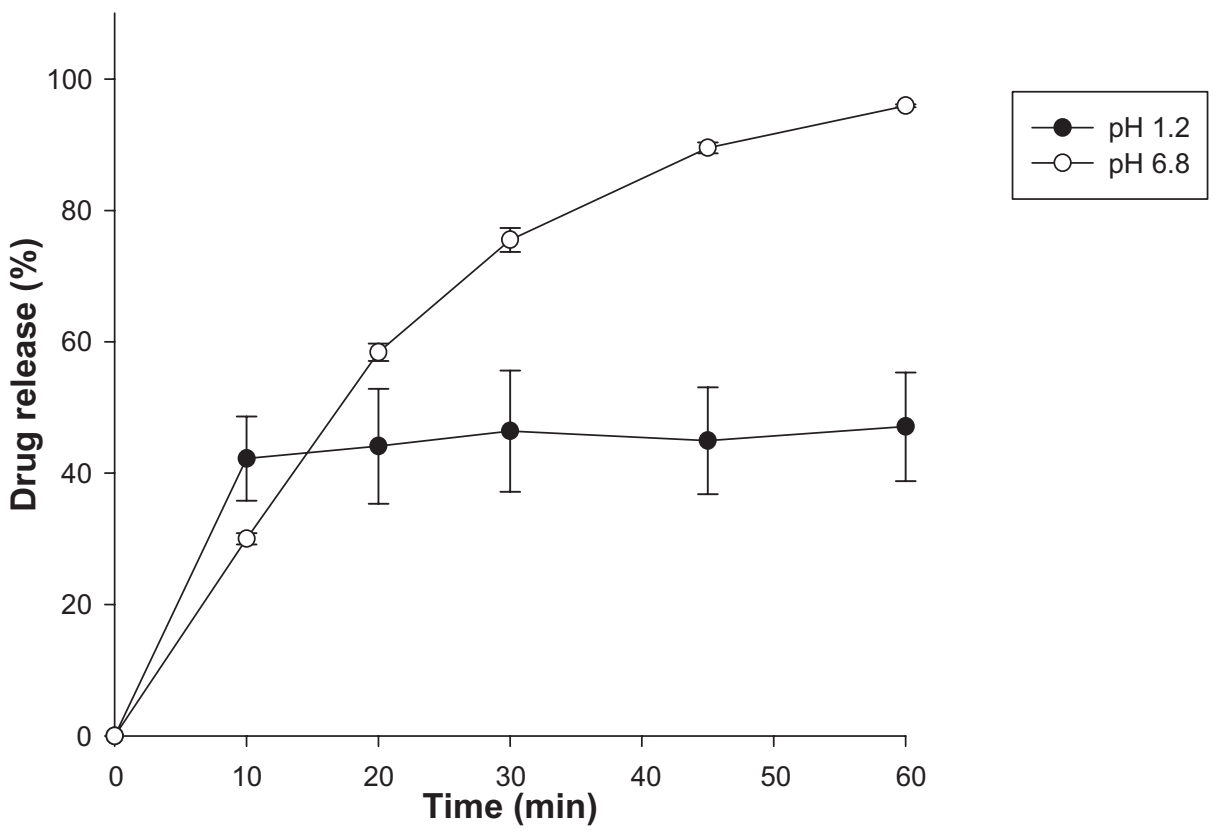

Figure 6 Drug release profile of FB-AMP ${ }_{(3)}$ at $\mathrm{pH} 1.2$ and $\mathrm{pH} 6.8$ (mean \pm standard deviation, $\mathrm{n}=3$ ).

Abbreviations: $\mathrm{FB}_{-\mathrm{AMP}_{(3)}}$, flurbiprofen incorporated into 3-aminopropyl functionalized magnesium phyllosilicate clay; min, minutes. 
Table I Pharmacokinetic parameters of $F B$ after an oral administration of $\mathrm{FB}$ or $\mathrm{FB}-\mathrm{AMP}_{(3)}$ in rats (mean $\pm \mathrm{SD}, \mathrm{n}=6$ )

\begin{tabular}{llll}
\hline Formulation & $\mathbf{C}_{\max }(\mu \mathrm{g} / \mathrm{mL})$ & $\mathbf{T}_{\max }(\mathbf{h})$ & AUC $(\mu \mathrm{g} \cdot \mathrm{h} / \mathrm{mL})$ \\
\hline $\mathrm{FB}$ & $17.8 \pm 5.1 \mathrm{I}$ & $1.22 \pm 0.66$ & $66.7 \pm 32.0$ \\
$\mathrm{FB}^{-A M P} \mathrm{P}_{(3)}$ & $38.8 \pm 10.8^{*}$ & $0.44 \pm 0.11^{*}$ & $137 \pm 17.1^{*}$ \\
\hline
\end{tabular}

Notes: $* P<0.05$, compared to $F B$ (untreated drug); dose equivalent to $10 \mathrm{mg} / \mathrm{kg}$ of FB.

Abbreviations: $\mathrm{FB}$, flurbiprofen; $\mathrm{FB}-\mathrm{AMP}_{(3)}$, flurbiprofen incorporated into 3-aminopropyl functionalized magnesium phyllosilicate clay; SD, standard deviation; $n$, number; $C_{\max }$, peak plasma concentration; $T_{\text {max }}$, time to reach peak plasma concentration; h, hours; AUC, area under the plasma concentration-time curve.

showed slower drug release than the untreated FB, which was similar to the previous observation by Holmström et al..$^{9}$ In the study, Holmström et $\mathrm{al}^{9}$ reported the sustained release of ibuprofen from the reassembled organoclay composite. However, in the case of $\mathrm{FB}-\mathrm{AMP}_{(3)}$, there was a more rapid drug release than with untreated FB (Figure 4). The fast drug release from FB-AMP ${ }_{(3)}$, might be explained as follows. First, as the ratio of AMP clay increased during the formation of FB-AMP clay some of the drug could have been adsorbed on the clay surface via the electrostatic interaction, whereas some of the drug was intercalated into the layered AMP clay. Therefore, in the aqueous media, the adsorbed drug on the clay surface was released rapidly at the early stage (ie, initial time points), whereas the drug release at the later stage came from the intercalated drug.

After oral administration, the drug should go through the stomach at $\mathrm{pH} 1-2$ before reaching the intestines. Therefore, the $\mathrm{pH}$ effect on the drug release profiles of untreated $\mathrm{FB}$, as well as FB-AMP clay, was also evaluated (Figure 5). With both untreated FB and FB-AMP ${ }_{(3)}$, the released drug amount was significantly decreased under acidic conditions (Figure 5). Given that FB has a pKa of $4.27,{ }^{21}$ the fraction of unionized drug should be increased as $\mathrm{pH}$ decreases, resulting in lower solubility of FB. Therefore, it is clear that the extent of drug release decreased under acidic conditions. However, compared to the untreated drug, FB-AMP $(3)$ still enhanced the drug dissolution three-fold at $\mathrm{pH}$ 1.2. This is because the high $\mathrm{pH}$ associated with AMP clay (about $\mathrm{pH} 10.5$ ) in aqueous solution might help the dissolution of FB through the increased microenvironmental $\mathrm{pH}$. On the other hand, the drug release rate from FB-AMP clay was slightly slower at higher $\mathrm{pH}$ (Figure 6). Conceivably, the release rate could depend on the electrostatic interaction of the drug molecule and the AMP clay, which can be varied by changing the $\mathrm{pH}$. FB will be more ionized at higher $\mathrm{pH}$, and thus the electrostatic interaction between drug and AMP clay will be stronger, causing the intercalated drug to stay longer inside the clay galleries.

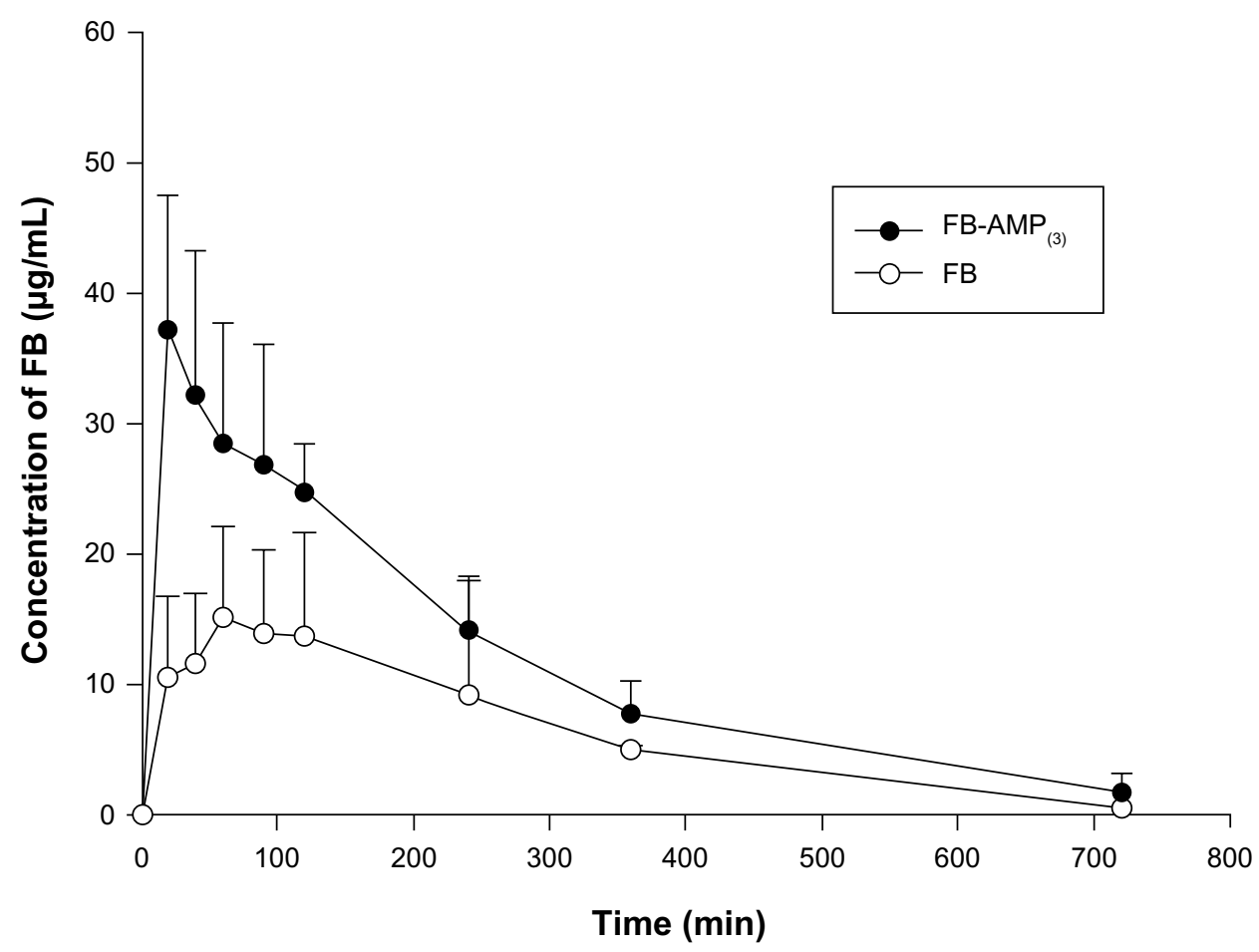

Figure 7 Plasma concentration-time profiles of $\mathrm{FB}$ after an oral administration of $\mathrm{FB}$ (untreated) and $\mathrm{FB}-\mathrm{AMP} \mathrm{(3)}$, in rats (mean $\pm \mathrm{SD}, \mathrm{n}=6)$. Dose was equivalent to $10 \mathrm{mg} /$ $\mathrm{kg}$ of $\mathrm{FB}$.

Abbreviations: FB, flurbiprofen; FB-AMP ${ }_{(3)}$, flurbiprofen incorporated into 3-aminopropyl functionalized magnesium phyllosilicate clay; SD, standard deviation; n, number; min, minutes. 
Taken together, $\mathrm{FB}_{-\mathrm{AMP}_{(3)}}$ exhibited rapid and complete dissolution in water and also improved the extent of drug release at low pHs compared to untreated FB.

\section{In vivo pharmacokinetic studies}

The pharmacokinetic parameters of FB following an oral administration of FB or FB-AMP ${ }_{(3)}$ are summarized in Table 1. Mean plasma concentration-time profiles of $\mathrm{FB}$ following an oral administration of FB or FB-AMP ${ }_{(3)}$ are also illustrated in Figure 7. FB-AMP ${ }_{(3)}$ enhanced significantly $(P<0.05)$ the systemic exposure of FB (Table 1). The $\mathrm{C}_{\max }$ and AUC of FB increased two-fold via the FB-AMP formulation, whereas $\mathrm{T}_{\text {max }}$ was shortened. Therefore, the faster and more efficient dissolution of FB via the FB-AMP formation appeared to be correlated well with more rapid and enhanced absorption of $\mathrm{FB}$ in rats. This result suggests that $\mathrm{FB}-\mathrm{AMP}_{(3)}$ is promising for improving the bioavailability of FB. Furthermore, considering that rapid onset of action is required for an analgesic drug, the shorter $\mathrm{T}_{\max }$ from $\mathrm{FB}-\mathrm{AMP}_{(3)}$ could be beneficial for the earlier onset of analgesic action.

A previous study indicated that AMP clay had little cytotoxicity in normal fibroblast and tumor cells. ${ }^{14}$ In the concentrations up to $500 \mu \mathrm{g} / \mathrm{mL}$, the toxicity of AMP clay in terms of cell viability and membrane damage appeared to be minimal. In addition, AMP clay did not induce apoptosis even at concentrations as high as $1,000 \mu \mathrm{g} / \mathrm{mL}$, implying that the potential toxicity of AMP clay is low. ${ }^{14}$ Given that the AMP clay is a nontoxic host material, ${ }^{14}$ the in vitro and in vivo observation in the present study strongly support that AMP clay might have a high potential as a drug delivery carrier to improve the bioavailability of poorly soluble drugs.

\section{Conclusion}

FB-AMP ${ }_{(3)}$ significantly enhanced the rate and the extent of drug release of FB, particularly at low pHs. Furthermore, FB$\mathrm{AMP}_{(3)}$ significantly $(P<0.05)$ enhanced the oral exposure of FB in rats compared with the untreated powder formulation. Therefore, FB-AMP ${ }_{(3)}$ appears to be effective in improving the dissolution and the bioavailability of FB in rats.

\section{Acknowledgment}

This study was supported by Mid-Career Researcher Program through the National Research Foundation grant funded by the Ministry of Education, Science and Technology (No 2010-0008596), by the Gyeonggi Regional Research Center program of Gyeonggi province (GRRCDONGGUK2011-B03, Biological Applications of New Therapeutic Target Modulators), and by the Bio \& Medical
Technology Development Program of the National Research Foundation (NRF) funded by the Korean government (MEST) (Number 2012053532).

\section{Disclosure}

The authors declare no conflict of interest in this work.

\section{References}

1. Gursoy RN, Benita S. Self-emulsifying drug delivery systems (SEDDS) for improved oral delivery of lipophilic drugs. Biomed Pharmacother. 2004;58(3):173-182.

2. da Fonseca MG, Airoldi C. Phyllosilicate-like structure anchored silylating agents: calorimetric data on divalent cation-aminated centre interactions in the lamellar cavity. J Chem Soc Dalton. 1999(21);3687-3692.

3. Sales JAA, Petrucelli GC, Oliveira FJVE, Airoldi C. Some features associated with organosilane groups grafted by the sol-gel process onto synthetic talc-like phyllosilicate. J Colloid Interface Sci. 2006(1);297: 95-103.

4. Melo MA Jr, Oliveira FJVE, Airoldi C. Novel talc-like nickel phyllosilicates functionalized with ethanolamine and diethanolamine. Appl Clay Sci. 2008;42(1-2):130-136.

5. da Fonseca MG, Da Silva Filho EC, Machado RSA Jr, Arakaki LNH, Espinola JGP, Airoldi C. Zinc phyllosilicates containing amino pendant groups. J Solid State Chem. 2004;177(7): 2316-2322.

6. Burkett SL, Press A, Mann S. Synthesis, characterization, and reactivity of layered inorganic-organic nanocomposites based on 2:1 trioctahedral phyllosilicates. Chem Mater. 1997;9(5):1071-1073.

7. Mann S, Burkett SL, Davis SA, et al. Sol-gel synthesis of organized matter. Chem Mater. 1997;9(11):2300-2310.

8. Bromley KM, Patil AJ, Seddon AM, Booth P, Mann S. Biofunctional mesolamellar nanocomposites based on inorganic/polymer intercalation in purple membrane (bacteriorhodopsin) films. Adv Mater. 2007;19(18):2433-2438.

9. Holmström SC, Patil AJ, Butler M, Mann S. Influence of polymer co-intercalation on guest release from aminopropyl-functionalized magnesium phyllosilicate mesolamellar nanocomposites. J Mater Chem. 2007;17:3894-3900.

10. Mann S. Self-assembly and transformation of hybrid nano-objects and nanostructures under equilibrium and non-equilibrium conditions. Nat Mater. 2009;8:781-792.

11. Patil AJ, Muthusamy E, Mann S. Fabrication of functional proteinorganoclay lamellar nanocomposites by biomolecule-induced assembly of exfoliated aminopropyl-functionalized magnesium phyllosilicates. J Mater Chem. 2005;15:3838-3843.

12. Patil AJ, Muthusamy E, Mann S. Synthesis and self-assembly of organoclay-wrapped biomolecules. Angew Chem Int Ed Engl. 2004;43: 4928-4933.

13. Patil AJ, Li M, Dujardin E, Mann S. Novel bioinorganic nanostructures based on mesolamellar intercalation or single-molecule wrapping of DNA using organoclay building blocks. Nano Lett. 2007;7(9):2660-2665.

14. Han HK, Lee YC, Lee MY, Patil AJ, Shin HJ. Magnesium and calcium organophyllosilicates: Synthesis and in vitro cytotoxicity study. ACS Appl Mater Interfaces. 2011;3(7):2564-2572.

15. Richy F, Rabenda V, Mawet A, Reginster JY. Flurbiprofen in the symptomatic management of rheumatoid arthritis: a valuable alternative. Int J Clin Pract. 2007;61(8):1396-1406.

16. Kang JH, Oh DH, Oh YK, Yong CS, Choi HG. Effects of solid carriers on the crystalline properties, dissolution and bioavailability of flurbiprofen in solid self-nanoemulsifying drug delivery system (solid SNEDDS). Eur J Pharm Biopharm. 2012;80(2):289-297.

17. Oh DH, Kang JH, Kim DW, et al. Comparison of solid self-microemulsifying drug delivery system (solid SMEDDS) prepared with hydrophilic and hydrophobic solid carrier. Int J Pharm. 2011;420(2):412-418. 
18. Pudipeddi M, Serajuddin ATM, Grant DJW, Stahl PH. Solubility and dissolution of weak acids, bases, and salts. In: Stahl, PH, Wermuth, CG, editors. Handbook of Pharmaceutical Salts: Properties, Selection, and Use. New York:Wiley-VCH; 2002:19-39.

19. Serajuddin AT. Salt formation to improve drug solubility. Adv Drug Deliv Rev. 2007;59(7):603-616.

20. Serajuddin AT, Jarowski CI. Effect of diffusion layer $\mathrm{pH}$ and solubility on the dissolution rate of pharmaceutical acids and their sodium salts II: Salicylic acid, theophylline, and benzoic acid. J Pharm Sci. 1985;74(2): $148-154$
21. Pignatello R, Ferro M, Puglisi G. Preparation of solid dispersions of nonsteroidal anti-inflammatory drugs with acrylicpolymers and studies on mechanisms of drug-polymer interactions. AAPS Pharm Sci Tech. 2002;3(2):E10.

\section{Publish your work in this journal}

The International Journal of Nanomedicine is an international, peerreviewed journal focusing on the application of nanotechnology in diagnostics, therapeutics, and drug delivery systems throughout the biomedical field. This journal is indexed on PubMed Central, MedLine, CAS, SciSearch $\AA$, Current Contents ${ } /$ Clinical Medicine,
Journal Citation Reports/Science Edition, EMBase, Scopus and the Elsevier Bibliographic databases. The manuscript management system is completely online and includes a very quick and fair peer-review system, which is all easy to use. Visit http://www.dovepress.com/ testimonials.php to read real quotes from published authors.

Submit your manuscript here: http://www.dovepress.com/international-journal-of-nanomedicine-journal 